\title{
New Data on HIV Reservoirs: Implications for Therapy
} Alain Lafeuillade*

\author{
Address: General Hospital, Toulon, France \\ Email: Alain Lafeuillade* - avps@club-internet.fr \\ * Corresponding author $\ddagger$ Presenting author
}

\author{
from 2005 International Meeting of The Institute of Human Virology \\ Baltimore, USA, 29 August - 2 September 2005 \\ Published: 8 December 2005 \\ Retrovirology 2005, 2(Suppl I):S75 doi:10.1 I86/I742-4690-2-SI-S75
}

For years now, AIDS researchers have suspected that most investigations have been focusing on the wrong site, i.e. blood. In fact, it has been well known for over a decade that lymphoid tissue is the key viral replication site from the start of infection, and also a major reservoir and source of virus at all stages of the disease. Lymphoid tissue studies in humans have been impeded by difficulties in obtaining material and, first and foremost, in reiterating sampling. Recent findings in the SIV-infected macaque model pinpoint the intestinal mucosal immune system as a key site of viral replication/persistence and CD4 depletion, even in subjects with undetectable blood virus during therapy. These studies demonstrate that acute SIV and HIV infections are coupled with a dramatic and selective loss of memory CD4 T cells in lymphoid tissue, due to direct virus-induced cytolysis or immune-mediated mechanisms (Mattapallil JJ et al, Nature 2005; 434: 1093-7). Treatment strategies based primarily on blood viral load and circulating CD4 cell counts are hence misguided. These findings plead for HAART initiation as early as possible, and will also have implications for vaccine development.

Data have recently been published on the potential to decrease the latent HIV reservoir in humans by initiating HAART at acute infection (Strain $\mathrm{MC}$ et al, J Infect Dis $2005 ; 191: 1410-8$ ). Although failure to recover infectious virus from these patients certainly does not reflect the elimination of latently infected cells, these data are encouraging in the search of new strategies combining HAART and immune interventions.

Despite its major effect on plasma viremia, HAART initiated at the chronic stage of the disease is known to have several major drawbacks, i.e. its inability to achieve HIV eradication due to poor targeting of the reservoir of latent but replication-competent virus, plus the inadequate diffusion of antiretroviral drugs in the various anatomic reservoirs. For example, it has been clearly demonstrated that some molecules in the combination are unable to reach the central nervous system or genital tract well enough to block viral replication, hence potentially creating sanctuaries of resistant virus. More recently, parallels have been made between the notion of cellular resistance to antiretroviral drugs and the resistance of some cancer cells to drugs. This resistance can involve efflux molecules like Pglycoprotein (MDR-1) and Multi-drug Resistance Protein (MRP). We investigated the expression of MDR-1, MPR-1 and MRP-4 mRNA levels in PBMC and lymph node cells (LNMC) in 15 HIV-infected patients on long-term effective PI-based HAART regimens (plasma viremia <20 copies/ml) versus controls (HIV-uninfected, HIV-infected HAART-naïve, HIV-infected on non-PI-based HAART). MDR-1, MPR-1 and MRP-4 mRNA levels were measured by PCR related to GAPDH expression and results given in arbitrary units. We found MDR-1 mRNA expression in PBMC to be much higher in HIV-infected but naïve patients than HIV-negative controls (46.64 vs 0.24 ), and higher in treated versus untreated patients, with no differences according to therapy type (no PI: 210.54, PI: 348.96). Surprisingly, MDR-1 expression in LNMC from PI-treated patients was significantly lower (0.97) than in paired PBMC. MRP-1 and MRP-4 expression showed significantly higher expression in HIV-treated versus HIVnegative patients, with no differences according to therapy type, and similar expression in HIV-infected untreated patients versus HIV-negative controls. No differences in MRP-1 and MRP-4 expression were found in LNMC and PBMC taken from the same patients on HAART. 
These advances should help us design new therapeutic approaches for HIV, capable of overcoming the reservoir problem.

Publish with Bio Med Central and every scientist can read your work free of charge

"BioMed Central will be the most significant development for disseminating the results of biomedical research in our lifetime. " Sir Paul Nurse, Cancer Research UK

Your research papers will be:

- available free of charge to the entire biomedical community

- peer reviewed and published immediately upon acceptance

- cited in PubMed and archived on PubMed Central

- yours - you keep the copyright

Submit your manuscript here:

http://www.biomedcentral.com/info/publishing_adv.asp 